\title{
FORENSIC LINGUISTIC EXPERTISE FOR UNIVERSITY STUDENTS' INTERDISCIPLINARY TRAINING
}

\author{
Olga Gorbatenko \\ Associate Prof., PhD, RUDN University, Law Institute Department of Foreign Languages, \\ RUSSIAN FEDERATION, \\ olgagorbatenko@inbox.ru
}

\begin{abstract}
The paper considers the forensic linguistic expertise interdisciplinary nature, types and issues that the expertise should decide on.

The above issues are subject to consideration from the angle of university-based training of lawyers, on the one hand, and linguists, on the other.

The paper aims to explore perceptions of law and language students with regard to the type of professional activities under study, and to investigate ways to integrate the basics of forensic linguistic expertise.

The research methodology integrated theoretical and empirical studies.

The analysis of relevant literature aimed to identify the academic contexts of the study.

The desk research covered relevant literature on the topic under study to map the major trends in the development of the forensic linguistic expertise as a scientific discipline and applied activities.

The empirical investigation included the questionnaire for language and law students who were offered to search for materials on the forensic linguistic expertise with the task to provide an integrated brief description of major aspects that the forensic linguistic expertise covers.

The results revealed the interdisciplinary nature of the course under study, highlighted the key items of the course on forensic linguistic expertise that law and language students considered relevant for the respective course studies.
\end{abstract}

The data can be useful for the course design and its specifics identification with regard to diverse target audiences.

Keywords: forensic linguistic expertise, university students training, interdisciplinary course design.

\section{INTRODUCTION}

\subsection{Forensic Linguistics Expertise: Phenomenon and Status in Society}

Forensic linguistics expertise has become one of fast-moving practice within legal proceedings in the third Millennium. Scholars consider that such a trend is related to the sharp increase in multimodal communication among individuals and organizations (Seyari, Bagheri, 2019; Yang, Gan, 2008).

Currently, forensic linguist is recognized as a professional expert in a respective field, with respective requirements to professional qualification and experience (Solan, 2020).

Researchers have underlined the social and legal role of the linguists who take part in the forensic linguistic expertise (Coulthard et al , 2016; Houtman, Suryati, 2018; Tiersma, Solan, 2002).Scholars pay specific 
attention to the interdisciplinary nature of the subject under study (Olsson, 2009), and underline the importance of pragmatics as the linguistics background for professional activities (Duro-Bello, 2018).

Moreover, practitioners highlight the importance of accurate data collection and provision in terms of its applied characteristics (Meluzzi, et al., 2020).

Bearing in mind the above, it seems logical that forensic linguistics implications are relevant for law students and legal education (Udina 2017). However, scholars specify various types of expertise (Hu, 2002).

As far as the Russian Federation is concerned, Academia has accumulated both theoretical and applied data on the topic under study (Galyashina, 2018).

\subsection{Research Framework}

The research framework rests on the following statements.

-Forensic linguistic expertise (FLE) is an independent type of forensic expertise associated with the study of the products of speech activity in order to establish facts (circumstances) that have evidentiary value in a specific (criminal, civil, arbitration or administrative) case.

-The subject of Forensic linguistic expertise refers to the facts (circumstances) that are significant for a criminal, civil, arbitration or administrative case and are established on the basis of a study of the products of speech activity.

-The Forensic linguistic expertise object is the products of speech activity (from a single word to a whole text or a group of texts, as well as a set of verbal and visual information). The experts are considered competent to research texts primarily in their native language.

-The most traditional types of the expertise include the following areas: identification of authorship, slam and protection of honor, dignity and business reputation, threat, offence, bribery, drug dissemination, etc.

\subsection{Research Design}

The paper aims to explore perceptions of law and language students with regard to the type of professional activities under study, and to investigate ways to integrate the basics of forensic linguistic expertise into the university curriculum.

The research methodology integrated theoretical and empirical studies.

The analysis of relevant literature aimed to identify the academic contexts of the study.

The empirical investigation included questionnaire for language and law students who were offered to search for brief courses on the forensic linguistic expertise with the task to provide an integrated brief description of major aspects that the forensic linguistic expertise covers.

The questionnaire included the following items:

$\square$ What types of expertise did you know from the course?

What are the specifics of each type of expertise?

What information should experts specify with regard to each type of expertise?

What requirements can be mentioned with regard to each type of expertise?

\section{RESULTS AND DISCUSSION}

The students were offered to search the materials on the forensic linguistic expertise and shape their findings in a brief project that would describe the major components of the potential course on the topic under study.

First, the students mentioned that they needed the information on the nature and features of different types of forensic linguistics expertise.

The list with the types of forensic linguistics expertise was drafted by the students during their on-line materials search.

Further the students accumulated specific features of each type of expertise, including the particular type of investigation purposes and techniques. 
Next the students mentioned that the sort and quality of materials were really important for the adequate results.

The paper provides bellow the brief description of students' contributions to the topic under study.

Forensic linguistic expertise in cases of slam and protection of honor, dignity, and business reputation

This kind of expertise is expected to conclude if the text contains negative information about the person, his/her name. Further, the expertise has to explain in what form this information is expressed

Forensic linguistic expertise in cases of offenses

The expertise of this type is expected to provide the answer to the question if some particular statements contain words with the meaning of a derogatory assessment of a person. And if such a situation takes place, then the expertise has to explain whether the words have linguistic signs of indecent form?

\section{Forensic linguistic expertise in cases about threat}

The expertise has to define if a particular statement or the whole text contains linguistic signs of threat.

Forensic linguistic expertise in cases of bribery and extortion

Such an expertise has to identify if the communication and its topics cover the transfer of funds. If the reply is positive that the conditions should be identified, as well.

Further this expertise is expected to explain if there is an incentive on the part of those specific participants to take specific actions in the course of conversation

Next the expertise has to reveal who is the initiator of the discussed topics.

Finally, the investigation is supposed to check if there are signs that the subject of speech is hidden in the text of the dialogue.

\section{Forensic linguistic expertise on drugs distribution cases}

The expertise has to identify if there are signs that the subject of speech is hidden in the text of the dialogue.

The analysis also should provide clear explanation on the particular meaning of the specific words in the context of the conversation.

Further the experts should conclude if the conversation refers to the sale of narcotic substances.

Forensic linguistic expertise related to the identification of the content and the meaning of a specific word/phrase/ fragment of a text

The expertise is supposed to explain the meaning of the particular words in the context of the provided document. Further, the investigation has to identify which fragment of the text some specific phrases and sentences refer to.

Further, the students explained that the list of questions was not complete. The questions can be specified and supplemented in accordance with the tasks to be solved.

Next, students paid particular attention to the requirements for the provided materials.

In case of the expertise on dialogues (telephone conversations, recording of a conversation when meeting persons, etc.), along with audio or video materials, it is necessary to provide a complete transcript of these conversations. The best option if such a transcript is obtained as a result of an examination of video and sound recordings.

The copies of the texts under examination provided to the expert must be of good quality, they should not contain darkened or folded edges, all words should be legible.

In case of examinations in cases of insult, a detailed description of the circumstances in which these statements were uttered, as well as the phrase in which these words were used, is required. This will allow the experts, firstly, to accurately determine the meaning of the word and its function, and, secondly, to establish the purpose of the statement under study as that one to humiliate the honor and dignity of the addressee.

Further in case of the above-mentioned sort of expertise, it is necessary to clearly identify the words under study: list them or indicate the sheet of the case on which they are written. All words must be written in full 
(without replacing letters with dots or descriptive designation of the word); if for some reason this cannot be done in the resolution, the expert should be provided with a certificate or a sealed envelope with these words.

The above data confirms that students realized the importance of forensic linguistics expertise in their further professional activities.

Meanwhile we consider it possible to mention a number of points that might be relevant for the development of the respective course for law students.

First, law students should be given the linguistics background in terms of discourse concept, its features, constituent elements, different trends in discourse forms, formats, genres, etc. as current discourse studies confirm the social role of discourse, its potential in combating crimes, protecting victims, etc. (Atabekova, 2019a,b, Atabekova et al., 2019), contributing to the community sustainable development (Atabekova 2020).

Further, during the digitalized Millennium it is important to bear in mind cyber forensic linguistics techniques that specialists already use in their professional activities (Klopper, 2009).

Next, it seems relevant to corpus-based approach to train students in forensic expertise (Cotterill, 2010, Tagg, 2009)

\section{CONCLUDING REMARKS}

The findings confirm that the course on forensic linguistic expertise students of different fields of education should be offered the material in varied modes which differ in terms of terminological apparatus training, and content material scope and distribution.

The findings can be used for further theoretical studies of the phenomenon specifics in terms of its data cognitive processing by specialists of different professional domains. The findings bear clear applied value in terms of university curriculum draft for law and language students.

Further studies seem relevant in terms of the course components and their specific contents in case such a course is addressed to different target audiences and specialists.

\section{REFERENCE LIST}

Atabekova, A. (2019a).Discourse Studies to Protect Minors against Violence in Sports Towards Discourse Studies Novelty. 6th International Conference on Education and Social Sciences (INTCESS-2019), Dubai, United Arab Emirates, February 04-06, 1185-1189.

Atabekova, A. (2019b).Do Discourse Studies Matter with Regard to Protect Minors against Violence in Sport? 6th International Conference on Education and Social Sciences (INTCESS-2019), Dubai, United Arab Emirates, February 04-06, 1190-1194.

Atabekova, A. (2020). University discourse to foster youth's sustainability in society amidst COVID19: International and Russian Features. Sustainability, 12(18), 7336.

Atabekova, A., Belenkova, N., Gorbatenko, R. (2019). Discourse as a tool to counter extremism: shaping methodology for research. AD ALTA-Journal of interdisciplinary research, 9(1), Special issue 6, 64-68.

Cotterill, J. (2010). How to use corpus linguistics in forensic linguistics. In The Routledge handbook of corpus linguistics (pp. 606-618). Routledge.

Coulthard, M., Johnson, A., Wright, D. (2016). An introduction to forensic linguistics: Language in evidence. Routledge.

Duro-Bello, O. (2018). Forensic Linguistics. Discourse Analysis and Pragmatics: Issues in Theory and Practice, 229.

Galyashina, E. I. (2018). Forensic linguistics in Russia: State of the art and new challenges. Tеория и практика судебной экспертизы, 13(4), 28-37.

Houtman, H., \& Suryati, S. (2018). The History of Forensic Linguistics as an Assisting Tool in the Analysis of Legal Terms. Sriwijaya Law Review, 2(2), 215-232. 
$\mathrm{Hu}$, Z. (2002). Forensic linguistics and four fields of linguistic expertise. [J]. Contemporary Linguistics, 2.

Klopper, R. (2009). The Case for Cyber Forensic Linguistics. Alternation, 16(1), 261-294.

Meluzzi, C., Cenceschi, S., \& Trivillini, A. (2020). Data in Forensic Phonetics from theory to practice. TEANGA, the Journal of the Irish Association for Applied Linguistics, 27, 65-78.

Olsson, J. (2009). Wordcrime: Solving crime through forensic linguistics. A\&C Black.

Seyari, A., \& Bagheri, M. S. (2019). Perspectives of Forensic Linguistics Research in Iran. Language Horizons, 3(1), 187-205.

Solan, L. M. (2020). The forensic linguist. The Routledge Handbook of Forensic Linguistics, 349.

Tagg, C. (2009). A corpus linguistics study of SMS text messaging (Doctoral dissertation, University of Birmingham).

Tiersma, P., \& Solan, L. M. (2002). The linguist on the witness stand: forensic linguistics in American courts. Language, 221-239.

Udina, N. (2017). Forensic linguistics implications for legal education: creating the e-textbook on language and law. Procedia-Social and Behavioral Sciences, 237, 1337-1340.

Yang, X. H., \& Gan, X. (2008). The Historical Transitions of Forensic Linguistics and Its Significance. Journal of Chongqing University (Social Science Edition), 3. 